\title{
Editorial
}

\section{Is the emperor nude? Impact factor or health impact factor?}

Success in research is today assessed by means of bibliometrics, identifying impact factors for the journals where we publish. Within medicine and biosciences impact factors are highly diverse, with the highest numbers in the area of cell biology, clinical medicine, pharmacology, molecular biology and genetics ${ }^{(1)}$. The area of nutrition is never particularly high on the impact factor list. This creates a vicious cycle for nutritionists, since the impact factor is an important basis for funding decisions.

We hear from British universities that the advice to researchers is to publish fewer papers but with higher quality, which is often inferred from the impact factor. This may lead to good nutrition scientists directing their attention from nutrition journals to cell biology or molecular biology journals in order for the individual researcher to build a good career, or even for the survival of researchers or research groups within universities. However, the Research Evaluation Framework (REF), which will assess the quality of UK research in the period from 2008 to 2012, will for the first time award $20 \%$ of the overall assessment on the basis of the impact of the research on policy and practice ${ }^{(2)}$.

Everybody must agree that applied research in the field of nutrition is extremely important for health development globally. It is time to ask whether the impact factor that dominates criteria used to judge research productivity is, in fact, a useful metric. Isn't impact on health a more important consideration? The REF framework is one step in that direction. Perhaps we should develop this even further; perhaps it is time to implement our own bealth impact factor in applied nutrition research. A health impact factor could consist of the number of citations, number of downloads and number of media events, combined with resulting actual changes in policy or practice and health effects in the long run. Any suggestions in this regard are very welcome, in the form of a letter, paper or short comment to this journal.

\section{Intervention papers?}

In this issue of Public Health Nutrition, you can find papers under most of our headings. We are concerned, however, that we get few good intervention papers to publish. We are not sure why this is so, but we understand that funding for interventions does not always include time for publication of results. This is a serious problem, since big gaps still exist in the area of intervention impact and outcome. In upcoming issues this year we will highlight the art of writing a good intervention paper, based on the demands set up by several systematic review authors.

Agneta Yngve

Editor-in-Chief

Marilyn Tseng

Geraldine McNeill

Allison Hodge

Irja Haapala

Deputy Editors

\section{References}

1. ISI Web of Knowledge.

2. Higher Education Funding Council for England (2011) REF2014 Research Excellence Framework. http://www. hefce.ac.uk/research/ref/ (accessed March 2011). 